\title{
UNA RECETA ANGELICAL
} UN ANGELIC RECIPE

Fecha de recepción: 10/4/19 Fecha de aceptación: 20/4/19

\section{NIEVES SORIA}

Psicoanalista practicante en la ciudad de Buenos Aires. Es miembro de la Escuela de la Orientación Lacaniana (EOL) y de la Asociación Mundial de Psicoanálisis (AMP). Coordina diversos grupos de estudio. Es Jefa de trabajos prácticos de la Cátedra II de Psicopatología de la Facultad de Psicología de la Universidad de Buenos Aires desde 2003. Es supervisora y dicta cursos y conferencias en varios hospitales de la ciudad y la provincia de Buenos Aires. Desde el año 2005 sostiene un espacio de enseñanza del psicoanálisis en su seminario diurno, dictado en la Escuela de la Orientación Lacaniana. Es autora entre otros de Psicoanálisis de la anorexia y la bulimia. Ed. Tres Haches. Bs. As., (2000); Confines de las psicosis Serie Del Bucle. Bs. As. (2008); Nudos del análisis, Serie Del Bucle. Bs. As., (2013); ¿Ni neurosis ni psicosis? Serie Del Bucle. Buenos Aires, (2015) Desde el año 2009 dicta seminarios en diferentes lugares de Brasil.
Resumen: El texto realiza una crítica de la propuesta de una contra-pedagogía de la crueldad por parte de Rita Segato, planteando que una lectura simplista del psicoanálisis, que desconoce tanto su estatuto ético como sus conceptos fundamentales, desemboca en una forclusión de la pulsión de muerte que decanta en un moralismo que no impide el retorno en lo real de la misma, ya que se encuentra guiada por una utopía denegada que busca el restablecimiento de un goce absoluto y sin falta, representado por el paraíso pre-patriarcial.

Palabras Clave: Forclusión - Pulsión de muerte Utopía - Amor.
Abstract: This text questions the proposal of an anti-pedagogy of cruelty by Rita Segato who makes a simplistic interpretation of psychoanalysis without considering its ethical principles or fundamental concepts. This results in a death drive forclosure leading to certain moralism that does not prevent such forclosure from returning in the realm since it is guided by a denied utopia to restore absolute and plentiful enjoyment represented by the pre-patriarchal paradise.

Key words: Forclosure - Death drive - Utopia - Lovening - Names. 
Rita Segato piensa cocinando huevos, yo nadando. En mí, los pensamientos se arremolinan, se mezclan, salpican, se hunden, siguen la respiración, se alejan... viene el vacío, ahora se oye el ritmo... y de pronto... algo se escribe allí, en el agua. Me gusta dejarme llevar por el canto de las sirenas... también hacer puerto, cada tanto, y encontrar algo apetitoso...

\section{EL HUEVO ESTÁ FRITO}

El huevo está frito, listo para consumir. Inútil ya como grotesco adorno del cuerpo del hombre, la ciencia lo ha disecado oportunamente, listo para ser incorporado, al menos por ahora. Si no está frito, está en el horno. Hijo de un padre-espermatozoide y de un óvulo debidamente seleccionado, transitará vías suficientemente asépticas hasta encontrar su lugar en el interior de un cuerpo, por ahora femenino.

Dos años antes de que Carl Djerassi patentara la famosa píldora, Simone de Beauvoir anticipaba que la perpetuación de la especie no presupondría la diferencia sexual, animándonos a imaginar una reproducción por partenogénesis o formada por hermafroditas, por lo que, con el auxilio de la ciencia, podría volverse a los felices tiempos del paraíso pre-patriarcal -goce pleno, sin falta-, arruinado por el descubrimiento de la participación del padre en la procreación . Así, el huevo está frito por efecto del discurso científico, y los discursos de género lo consumen, cocinado por almas maternales como Rita Segato, que sabe hacer receta de su lección.

\section{LA ENSALADA LIGHT DE LA "NARRATIVA PSICOANALÍTICA"}

El eventual riesgo para el colesterol de este menú puede verse parcialmente neutralizado por una saludable ensalada light: aquella que ya desde el segundo capítulo de El segundo sexo, pasando por Luce Irigaray, Monique Witting y Judith Butler -entre otras- nos entrega una conveniente versión del psicoanálisis, predigerida y regurgitada en una pedagogía moralista que forcluye tanto su estatuto ético de práctica -rebajándola a una religión, mito o narrativa - como sus conceptos fundamentales, degradando sus nombres a meros ingredientes de una receta lista para el delivery. Con pasión fundamentalista, Rita Segato lee el mito de Tótem y tabú con la lente de Carole Pateman, situando el acto de violación como "primera ley", fundamento del orden social, desconociendo así el concepto psicoanalítico de ley, que implica una operación de inter-dicción, castración que negativiza la violencia como un absoluto. En esta cocina fácil para la mujer moderna, el siguiente paso es definir al mandato de masculinidad como un mandato de violación, condenando al hombre en una pedagogía de la crueldad que no tiene nada de "contra", aun cuando, desconcertada por las consecuencias de su lección, sus buenas intenciones llamen a sus huestes a no replicar el ethos patriarcal...

No nos detendremos en las otras ensaladas -que también son escaladas- feministas, referentes a la confusión del pater con el Nombre del Padre, a la diferencia sexual (leer El sexo y la eutanasia de la razón, de Joan Copjec, como notable excepción) y los conceptos de falo y castración, entre otros conceptos fundamentales.

\section{PROHIBICIÓN VEGETARIANA}

Sí lo haremos con la confusión entre deseo y goce, que conlleva la forclusión del concepto de pulsión en esta lectura de manual de primaria del psicoanálisis. En efecto, para probar este plato hay que guiarse por un menú que prohíbe el $a$ peritivo -dimensión melancólico-anoréxica de la subjetividad actual -: al padre no hay que "tragárselo" (a lo sumo, podrá "fumárselo", mal menor) porque, al ya no considerárselo una causa del deseo, solo causa indigestión.

Buscando alejarse científicamente de la imaginación, no logra sin embargo superar la prohibición de prohibir de los 60: de eso se trata en esta "contra-pedagogía de la crueldad": de desmontar el 
mandato masculino, siguiendo un mandato de no mandato como mandato oculto, volviéndose por esta operación el significante amo "más inatacable aún". Así se apuesta a una deconstrucción que solo abre dos posibilidades: o bien la errancia del ayuno anoréxico -la ausencia de referencia, con la angustia ante la carne como único contacto posible con lo real- o bien la reacción devoradora bulímica de la carne en el ataque sexual (femicida u homicida) -ya no regulada por las reglas del asadito, con sus manos, presencias, roces y decires, femeninos, masculinos y otros, bailando en una ceremonia festiva-.

\section{¿QUÉ LE DA GUSTO AL PLATO?}

La maestra abnegada no sabe que no alcanza con cocinar los huevos para darle gusto al plato, así como no alcanza con memorizar las tablas para aprender a multiplicar. Al excluir la función del a-peritivo, desconoce que un discurso se soporta de un real, que es el objeto $a$-siempre ausente del ingrediente "psicoanalítico" de la receta feminista-. Es que la maestra ciruela no enseña -no hace acto, no cava un surco- porque cree en la pedagogía, es nominalista: con Foucault y su cohorte deleuzo-guattariana, cree que bastan las palabras para crear las cosas, como si alcanzara con seguir la receta para volver el plato apetitoso.

Dando un paso más llega a creer en la performatividad, y la ciencia la avala -en efecto, la nueva maestra es cognitivista y su receta anorexígena para ángeles, se acerca siniestramente a la programación neurolingüística-, logra entonces ser políticamente correcta. En su urgencia por alfabestizar a los hijos del patriarcado, pasa por alto la lógica del fantasma y la gramática de la pulsión. En su ignorancia supina de los términos empleados, propone "deslibidinizar la agresión sexual", "problematizar la libido, o sea el deseo ".

Lejos queda el deseo precipitado en el acto, con su contingencia, con su dimensión pulsional. Aquí la vocación voluntarista desconoce que los cambios discursivos implican un real pulsional en juego. En primer lugar, algo tan poco angelical como la pulsión de muerte. La estructura de poder no es "la causa", sino una consecuencia del real de la pulsión de muerte. Malas noticias: hay falla en algún lado y su oleaje inunda al ser hablante, dejándole solo dos posibilidades pulsionales: el masoquismo (destrucción interior) o el sadismo (destrucción volcada al exterior, pulsión de apoderamiento) . Podrán limitarse por la castración o trastocarse por la sublimación, nunca desaparecer.

Así, la receta angelical no logra evitar la indigestión: ni la anorexia, ni el vegetarianismo ni el veganismo impiden un celiaquismo generalizado, que tampoco termina de cerrar la hemorragia digestivo-libidinal propia de la época. Un efecto de la receta feminista es el contragolpe de odio al hombre, que Segato, Butler y algunas otras intentan frenar candorosamente.

No, no se puede deslibidinizar por mandato, no se puede forcluir la pulsión. Querida maestra, si leyeras sin prejuicio al psicoanálisis quizás podrías responderte la pregunta que queda sin respuesta en tu libro Contra-pedagogías...: ¿por qué cuando la contra-pedagogía de la crueldad avanza, resulta que la crueldad también lo hace? Tu ingenua propuesta de volver al paraíso no es más que otro camino al infierno. Es tu propia contra-pedagogía de la crueldad la que se da vuelta como un guante con su voluntarismo cognitivista que desconoce algunos reales aún vigentes en el ser hablante. Quizás con el avance de la ciencia el sexo y la muerte dejen de serlo -no parece imposible-, pero aún quedan lo imposible de decir, de escribir, aún queda el misterio del cuerpo hablante .

\section{QUIJOTA EN LA GÓNDOLA}

La receta feminista no funciona porque creyendo luchar contra el pater en el latifundio feudal, desconoce que está atrapada en la góndola. No entiende que no existe la alianza del capitalismo con el patriarcado por dos razones: porque el patriarcado ya no existe, y porque el capitalismo solo hace alianza con el capital. Todos los gustos están "representados" en la góndola, de perfecto packaging, ya que, por el contrario, es el avance del capitalismo el que ha vuelto necesario el liberalismo con sus efectos discursivos, entre los cuales se encuentra la caída del orden paterno: liberados los individuos del poder del pater, los antaño siervos y las mujeres aumentan considerablemente la horda de consumidores, estas últimas fervientemente perdidas en la góndola, buscando, con todo derecho, un objeto que suture la falta.

Se podrá llegar hasta el final del menú, no se encontrará ese objeto perdido. Es que hay en él una utopía denegada: el paraíso terrenal. ¿Cómo encontrar en el supermercado el paraíso del arraigo 
espacial y comunitario?, ¿en un encuentro oceánico callejero periódico?, ¿en la obscenidad de las redes, de los testimonios públicos, de los escraches y tribunales sin necesidad de la intervención de Otro de la ley (anatemizado por paterno y castrado)?

Liberado el cuerpo del sexo, el goce se anuda al consumo, y todo lo atinente a la sexualidad quedará en más atravesado por este goce. Se paga entonces para masturbarse, o se publicitan las notables ventajas del dildo -símbolo por excelencia del fetichismo de la mercancía- por sobre el pobre pene, sujeto a los avatares de la castración y su espantoso origen corporal.

Eros, ese pequeño demonio, se pierde en el camino. Ni una referencia al amor en la receta segatiana. Ingrediente prohibido por peligroso, arbitrario, selectivo, impuro, políticamente incorrecto, sacrificial, puede volverse instrumento de sometimiento por parte del horroroso pater. Podrá sustituirse por un inofensivo sentimiento oceánico de comunión femenina en dosis adecuadas, que quizás traiga resabios del gusto prohibido en algún excitante escrache o tribunal feminista. Quedará definitivamente fuera de la receta aquel aroma a castración que conlleva la metáfora del amor.

Es que esta maestra que cree hacer la revolución predicando la desobediencia, en su prejuicio, se ha negado a pasar por la horma fálica, que conlleva la castración. Así, no puede saber que a la postre, no hay pedagogía del amor, y que sin él la relación entre los sexos es propiamente invivible. Solo queda la guerra.

\section{Notas}

1. Lacan, J.: (1969-70). Seminario 17. Reverso del psicoanálisis. Buenos Aires: Paidós, 1992. p. 135.

2. De Beauvoir, S.: El segundo sexo (1949). Madrid: Ediciones Cátedra, 2005, pp. 71-72.

3. Ibíd., p. 101.

4. Segato, R.: Contra-pedagogías de la crueldad. Buenos Aires: Prometeo, 2018, p. 45.

5. Ibíd., p. 137.

6. Segato, R.: Las estructuras elementales de la violencia. Bernal: Universidad Nacional de Quilmes, 2003, pp. 28-29.

7. Segato R.: 2018, p. 26.

8. "El mito de Edipo incomoda porque aparentemente instaura la primacía del padre, que sería una especie de imagen patriarcal. Me gustaría mostrarles por qué, por lo menos a mí, no me parece en absoluto una imagen patriarcal, muy lejos de eso". (Lacan, J. (1971). Seminario 18. De un discurso que no fuera del semblante. Buenos Aires: Paidós, 2009, p. 160.)

9. Soria, N.: "Anorexia y Nombre del Padre. El rechazo del a-peritivo", en Psicoanálisis de la anorexia y la bulimia. Buenos Aires: Del Bucle, 2016.

10. Lacan 1969-70, p. 192

11. Foucault, M.: Historia de la sexualidad, (1976) 1: La voluntad de saber. Buenos Aires: Siglo Veintiuno Editores, 2013.

12. Deleuze, G. \& Guattari, F.: El Antiedipo (1972) Buenos Aires: Paidós, 2005.

13. Soria, N.: "Ángeles del capitalismo", en e-Mariposa. Temas de Psiquiatría y Psicoanálisis, n 11. Buenos Aires: Grama, septiembre de 2018, pp. 43-44.

14. Segato, R.: La guerra contra las mujeres (2016) Buenos Aires: Prometeo, 2018 , p. 226.

15. "Es simplemente, como bien se nota, el programa del principio de placer el que fija su fin a la vida. Este principio gobierna la operación del aparato anímico desde el comienzo mismo; sobre su carácter acorde a fines no caben dudas, no obstante lo cual su programa entra en querella con el mundo entero, con el macrocosmos tanto como con el microcosmos. Es absolutamente irrealizable, las disposiciones del Todo - sin excepción- lo contrarían." (Freud, S. (1930). "El malestar en la cultura", en Obras completas, vol. 21. Buenos Aires: Amorrortu, 1986, p. 76).

16. Freud, S.: "El problema económico del masoquismo" (1924) en Obras completas, vol. 19. Buenos Aires: Amorrortu, 1986.

17. "Lo real, diré, es el misterio del cuerpo que habla, es el misterio del inconsciente." (Lacan, J. (1972-73). Seminario 20. Aun. Buenos Aires: Paidós, 1982, p. 158.)

18. El imperio de los sin sexo, producido por Kami 2010, recuperado de: https://www.youtube.com/watch?v=jsvq5KeHdiA.

19. Preciado, B.: Manifiesto contra-sexual. Madrid: Opera Prima. (2002). 